\title{
Environmental evaluation and benchmarking of the traditional dryland Mediterranean crop farming system in the Alentejo region of Portugal
}

Maurícia Rosado

Department of Animal Science, Instituto de Ciências Agrárias e Ambientais Mediterrânicas (ICAAM-UÉ), University of Évora, Apartado 94, 7000 Évora, Portugal Email: mmcr@uevora.pt

\section{Carlos Marques and Rui Fragoso*}

\author{
Department of Management, \\ Centre for Advanced Studies in Management and Economics \\ (CEFAGE), \\ University of Évora, \\ Apartado 94, 7000 Évora, Portugal \\ Fax: + 351-266-740-807 \\ Email: cmarques@uevora.pt \\ Email: rfragoso@uevora.pt \\ *Corresponding author
}

\begin{abstract}
In this paper the effects of traditional Mediterranean crop farming system of the Alentejo region of Portugal on environment are evaluated and benchmarked. With this objective a typical farm of the region using a traditional system based on a crop-rotation of durum wheat with sunflower and peas was selected. Environmental indicators were used to evaluate production activities environmental effects. These include nitrogen balance and energy input determined using input and output processes analysis, and greenhouse gas emissions, acidification and eutrophication impacts and an aggregate eco-indicator evaluated using life cycle assessment (LCA). Results show the relevance of rotating other crops with cereals to control environmental effects and promote typical Mediterranean crop farming system sustainability. Benchmarking of environmental indicators for Mediterranean traditional crop farming system of the Alentejo indicates that results are within bounds reported in the environmental scientific literature interval at levels below average, indicating relatively low environmental impacts comparing with other farming systems.
\end{abstract}

Keywords: benchmarking; agri-environmental indicators; ecological indicators; dry crops; Mediterranean area.

Reference to this paper should be made as follows: Rosado, M., Marques, C. and Fragoso, R (2015) 'Environmental evaluation and benchmarking of the traditional dryland Mediterranean crop farming system in the Alentejo region of Portugal', Int. J. Sustainable Society, Vol. 7, No. 2, pp.173-187. 